\title{
The Impact of Discourse Markers and Relative Clauses on the Reading Comprehension of EFL Learners
}

\author{
Ali Derakhshan \\ Assistant Professor at English Language and Literature Department, Golestan University, Iran \\ a.derakhshan@gu.ac.ir \\ Seyyed Farzad Kalali Sani \\ Alikaram Esfandiari Ghalaee \\ Chabahar Maritime University, Iran \\ farz1dk@gmail.com, \& esfandiariali77@gmail.com
}

Masoume Izadi

English Department, Torbat-e Heydarieh Branch, Islamic Azad University, Torbat-e Heydarieh, Iran masoumeizadi@gmail.com

\section{Doi:10.5901/mjss.2015.v6n1p568}

\begin{abstract}
In the realm of reading comprehension, syntactic knowledge has generated a great deal of debate among the researchers who believe in the effectiveness of teaching vocabulary through different methods and strategies, and those who believe in the effectiveness of syntactic knowledge in reading comprehension. The present study investigated the contribution of learners' syntactic knowledge, namely discourse markers and relative clauses in reading comprehension. A quasi-experimental design was used. Two groups of students were assigned as experimental and control groups. The performances of students in the experimental group were compared with the performances of students in the control group. A series of t- tests was run to determine the impact of syntactic knowledge on reading comprehension. Comparing the mean score of the experimental group with that of the control group on the post-test revealed that the experimental group outperformed the control group $(p=.000<$ .05). The findings could shed light on our understanding of the role of syntactic knowledge in reading comprehension and provide some pedagogical implications for learners, teachers, and materials developers. The paper finishes with some strands of research in the realm of reading comprehension.
\end{abstract}

Keywords: Reading Comprehension; Syntax; Discourse Markers; Relative Clauses; Grammar

\section{Introduction}

Not only had reading been the cynosure of old methods, but also it had received more attention from modern methods. It, therefore, has always been a fresh topic for research regarding various aspects which may influence it or it may influence them. Bodies of research previously conducted in this area have shown some special purposes for reading a text. As Rivers and Temperly (as cited in Nunan, 1999, p. 187) suggested, there are seven main purposes for reading:

1. To obtain information because we are curious about some topic;

2. To obtain instructions on how to perform some task for our work in our daily life (e.g., knowing how an appliance works);

3. To act in a play, play a game, do a puzzle;

4. To keep in touch with friends by correspondence or to understand business letters;

5. To know when or where something will take place or what is available;

6. To know what is happening or has happened;

7. For enjoyment or excitement.

Bernhardt and James (1987) argued that comprehension is a topic dependent process. It is the reader who starts processing the text from the beginning, so it involves making proper decisions during reading it. Comprehension also depends on the selection of critical features for rapid processing of the texts and a given test. Finally, metacognitive 
awareness plays a salient role in the process of comprehension. This metacognition can be gained through background and topic knowledge as well as the learner's linguistic knowledge and cognitive strategies.

Linguistic knowledge involves factors such as lexis, syntax and grammar which are viewed as quite necessary for language learning since they provide the basis for comprehension. In more technical words, in order for language learners to gain effective discourse comprehension, they must show mastery of these linguistic features (Carrell, 1983; Eskey\& Grabe, 1988). Grammar is traditionally subdivided into different but interrelated areas of study - morphology and syntax. The former is the study of how words are formed out of morphemes, and the latter is concerned with the formation of sentences and phrases out of words (Radford, 2004).

The term syntax refers to the interrelatedness of words to form constituents and to the relationship between these constituents. Berman (1984) states that:

in order to get at the basic propositional content of a sentence, readers must be able to manipulate the following interrelated components of sentence structure: constituent structure- what the parts of a sentence are, and how they interrelate hierarchically; structural items- function words and affixes which serve as markers of grammatical relations and of constituent and rhetorical structures; and dependencies- relations expressed between discontinuous elements such as so and that ... above (p. 142).

Grammar has always been one of the most difficult elements in learning English. Teaching grammar in schools has largely been ignored and teachers have relied on heavy drilling and repetition of structures. Students memorize these structures without understanding their value or their meaning. There has been a challenging question about teaching English grammar, whether grammar should be taught or not. However, empirical studies conducted by Ellis (2008), Long (1987), and Pica (1985) have shown the effectiveness of formal grammar teaching.

\section{Background}

\subsection{Discourse markers}

There are a number of research projects being published about discourse markers (DMs), a topic which has turned into a growth industry in linguistics. Different researchers have used various names for DMs such as discourse operators (Redeker, 1990), discourse particles (Schorup, 1985), pragmatic particles (O "stman, 1995) , and sentence connectives (Halliday, 1976). To define what exactly DMs are, Levinson (1983) states that:

there are many words and phrases in English, and no doubt most languages, that indicate the relationship between an utterance and the prior discourse ... It is generally conceded that words such as but, therefore, in conclusion, to the contrary, and ... have at least a component of meaning that resist truth conditional treatment ... what they seem to do is indicate, often in very complex ways, just how the utterance that contains them is a response to, or a continuation of, some portion of the prior discourse (p. 53).

Zwicky (1985) expressed an interest in DMs as a class when he wrote:

Within the great collection of things that have been labeled 'particles', we find at least on grammatically significant class of items, in English and in languages generally. These have been variously termed 'discourse particles' and 'interjections'; here I will call them 'discourse markers' ... On the grounds of distribution, prosody, and meaning, discourse markers can be seen to form a class (p. 292).

Discourse markers have been classified in different groups under various headings. Table1 depicts this classification.

Table 1. Classification of Discourse Markers

\begin{tabular}{|cccc|}
\hline ADDING & SEQUENCING & ILLUSTRATING & CAUSE \& EFFECT \\
\hline And & first, second, third... & for example & Because \\
also & finally & such as & so \\
as well as & next & for instance & therefore \\
moreover & meanwhile & in the case of & thus \\
too & after & as revealed by & consequently \\
furthermore & then & illustrated by & hence \\
additionally & subsequently & rustion & \\
\hline
\end{tabular}




\begin{tabular}{|cccc|}
\hline COMPARING & QUALIFYING & CONTRASTING & EMPHASIZING \\
\hline Similarly & But & whereas & above all \\
likewise & however & instead of & in particular \\
as with & although & alternatively & especially \\
like & unless & otherwise & significantly \\
equally & except & unlike & indeed \\
in the same way & apart from & on the other hand & notably \\
& as long as, if & conversely & \\
\hline
\end{tabular}

Fraser (1999) summarizes that DMs belong to pragmatic class, lexical expressions drawn from the syntactic classes of conjunctions, adverbials, and propositional phrases. They have a core meaning which is procedural, not conceptual, and their more specific interpretation is 'negotiated' by the context, both linguistic and conceptual.

\subsection{Relative clause}

Relative clauses are a further type of wh-clauses which contain a relative pronoun (who/whose/which) that relates to an antecedent in a higher clause (generally one which immediately precedes the wh-expression)(Radford, 2004).

Relative clauses are used to give additional information about something without starting another sentence. One of the advantages of using a relative clause is that the text becomes more fluent and certain words are not repeated.

Different types of relative pronouns, their use and germane examples are shown in Table2.

Table 2. Relative Pronouns

\begin{tabular}{|c|c|c|}
\hline $\begin{array}{l}\text { Relative } \\
\text { Pronoun }\end{array}$ & Use & Example \\
\hline $\begin{array}{l}\text { Who } \\
\text { Which }\end{array}$ & $\begin{array}{l}\text { subject or object pronoun for people } \\
\text { subject or object pronoun for animals and things }\end{array}$ & $\begin{array}{l}\text { I told you about the woman who lives next door. } \\
\text { Do you see the cat which is lying on the roof? }\end{array}$ \\
\hline $\begin{array}{l}\text { Which } \\
\text { Whose } \\
\text { Whom } \\
\text { That }\end{array}$ & $\begin{array}{l}\text { referring to a whole sentence } \\
\text { possession for people animals and things } \\
\text { object pronoun for people, especially in non-defining relative } \\
\text { clauses (in defining relative clauses we colloquially prefer who) } \\
\text { subject or object pronoun for people, animals and things in } \\
\text { defining relative clauses (who or which are also possible) }\end{array}$ & $\begin{array}{l}\text { He couldn't read which surprised me. } \\
\text { Do you know the boy whose mother is a nurse? } \\
\text { I was invited by the professor whom I met at the } \\
\text { conference. } \\
\text { I don't like the table that stands in the kitchen. }\end{array}$ \\
\hline
\end{tabular}

To clarify the difference of subject and object pronouns, the following examples are provided:

The apple which is lying on the table is red.

The apple which George lays on the table is red.

In sentence (1), the relative pronoun is followed by a verb, so the relative pronoun is a subject pronoun. However, in sentence (2), the relative pronoun is not followed by a verb (but by a noun or pronoun), therefore the relative pronoun is an object pronoun. Object pronouns can be dropped in defining relative clauses, which are then called Contact Clauses.

(3) The apple which George lays on the table is red.

A relative adverb can be used instead of a relative pronoun plus preposition. This often makes the sentence easier to understand.

This is the shop in which I bought my bike.

This is the shop where I bought my bike.

Different types of relative adverbs, their use and examples are shown in Table3.

Table 3. Relative Adverbs

\begin{tabular}{|c|c|c|c|}
\hline Relative Adverb & Meaning & Use & Example \\
\hline When & in/on which & refers to a time expression & the day when we met him \\
Where & $\begin{array}{c}\text { in/at which } \\
\text { for which }\end{array}$ & $\begin{aligned} \text { refers to a place } \\
\text { refers to a reason }\end{aligned}$ & the place where we met him \\
the reason why we met him
\end{tabular}


Defining relative clauses (also called identifying relative clauses or restrictive relative clauses) give detailed information defining a general term or expression. Defining relative clauses are not put in commas and are often used in definition.

(4) A seaman is someone who works on a ship.

On the other hand, non-defining relative clauses (also called non-identifying relative clauses or non-restrictive relative clauses) give additional information on something, but do not define it. Non-defining relative clauses are put in commas. Object pronouns in non-defining relative clauses must be used.

(5) Jim, who/whom we met yesterday, is very nice.

\subsection{Reading comprehension}

As a process, reading comprehension is a sophisticated multifaceted phenomenon which draws upon several knowledge sources. According to Faerch and Gasper (1986), these knowledge sources involve a wide range of linguistic, communicative and contextual information: "...linguistic and other knowledge, and contextual information deriving from the situational context and the linguistic co-text" (p. 261). Eskey (1970) has been highlighted that: "The ability to read the written language at a reasonable rate with good comprehension has long been recognized to be as important as oral skills, if not more important" (p.1). Considering different views about the nature of language teaching and learning, there are various definitions for language skills and processes. The most salient controversy is held between behaviorists and cognitivists. Behavioristic psychology, deeply rooted in empiricism, was based on the idea that abstract does not exist; only the concrete and observable things are worthy of scientific inquiry (Zarei, 2007). Behaviorists, on the other hand, deny the role of the mind since it is abstract, so they define reading comprehension as the establishment of relationship between the written symbols and their corresponding sounds. Unlike behaviorists who believe in mechanical process of habit formation, cognitive psychologists consider language as a cognitive process of rule formation. They emphasize the role of mind in language processing, comprehension and production, so they define reading comprehension as an active mental process through which the written input is processed to recreate the writer's intended meaning (Nunan, 1999).

There are a number of skills and strategies by which ESL students become efficient readers. Being aware of the purpose of reading and using three processes which mentioned above can help readers to save time and focus on main ideas of the text as well as detail information. One of the techniques which are appropriate for intermediate to advance learners is using efficient silent reading to have better and faster comprehension. Some other skills for reading comprehension are as following: skimming, scanning, semantic mapping, guessing the meaning, analyzing the vocabularies, distinguishing between literal and implied meaning and identifying discourse markers to process relationships. The purpose of reading heavily influences the way readers read. They do not read a passage the same way they study a poem (Chastain, 1988). Chastain said that "it is readers' inclinations in the real world that identifies what they need or want to read" (p. 220). They spend a great deal of time to meticulously analyze the passages and delve into them carefully. One of the skills by which readers can tackle the problems of reading comprehension is scanning. To put in very simple words, scanning involves checking a text to extract specific information(Brown, 2001). This skill includes exercises like looking for names, places, dates or some other supporting information. While scanning deals with careful reading in order to find detail information in a text, skimming is a quick run of readers' eyes across a whole text such as an essay, article or a chapter of a book (Brown, 2001). If readers are not completely convinced that what they read is valuable, they may skim the text to find relevant information in the other pages of the text. One of the most significant advantages of skimming is predicting the purpose of the passage, the main topic and probably some of the germane and supporting ideas.

\subsection{The relevance of reading and syntax}

It is assumed that the only striking factor in comprehending a text is to understand the meaning of words, however, a relatively small but growing body of research indicates that in addition to vocabulary knowledge, shortcomings in children's knowledge or awareness of certain aspects of language development (e.g., syntax) are considered significant sources of reading and writing difficulty and are presumed to account for a significant portion of variance in children's reading comprehension performance. More advances in language and literacy research suggest that while vocabulary knowledge deficits are at the center of reading problems, deficits in syntactic awareness skills, defined as children's understanding of the syntactic structure of sentences and their ability to reflect on and manipulate that structure, are likely to play a significant role in explaining reading comprehension variance among developing and striving readers than originally assumed (Mokhtari, K. \& Niederhauser, D., 2013).Alderson (1993) refers to "the importance of knowledge of particular syntactic structures or the ability to process them, to some aspects of second language learning" (p. 37). Works 
which mainly have focused on syntactic knowledge of impaired children indicate that they have deficiencies in both understanding and the application of syntax regarding their reading comprehension performances. According to what Cromer and Winer (1966) have proposed poor readers do not apply their syntactic knowledge to take advantage of it in decoding written material. Anderson\& Pearson (1982) demonstrated that poor readers have syntactic problems regarding the written language, while Vogel (1975) revealed that the reading comprehension of impaired children had deficiencies in areas which measure "the syntax of expressive language" and found a significant correlation between productive syntax scores and reading comprehension scores. Processing Deficit Hypothesis (PDH) was proposed to support the notion of some researchers who argue that the main reason why some students are poor in reading performances is that they have difficulties in underlying phonological processing (Shankweiler \& Crain, 1989). The PDH states that unskilled readers do not experience deficits in representing or processing syntactic information but do experience difficulty in processing and retaining phonological information in working memory. This deficiency occurring at the level of working memory keeps information from being delivered at the necessary pace and with the required precision for higher level processing. For example, Shankweiler and Crain (1986) propose that difficulty in the processing of complex syntactic structures should be interpreted as difficulty at the phonological rather than the syntactic level.

In contrast to PDH, some researchers attributed students' weaknesses in reading comprehension performances to syntactic deficiencies (Bentin, 1990; Bowey, 1986a; Menyuk, 1991). They proposed syntactic deficit hypothesis (SDH) to advocate the idea that the main reason of students' poor performance in reading comprehension has deep roots in the absence of grammatical knowledge or dire lack of processing touch which interferes with higher level text comprehension. Regarding the SDH the acquisition of syntactic structures has stages and is gradual with inherently simpler structures preceding more complex ones in language development. The more complex structures the beginners and poor readers face, the more difficulty they have in answering the questions of reading comprehension tests. The criterion for the complexity of syntactic structure is based on the claim that one form or construction is simpler than another if children can produce and comprehend it first. For example, a sentence consisting of both a main clause and a subordinate clause such as The woman saw a man who ate a sandwich is considered more complex than a coordinate structure as in The woman saw a man and ate a sandwich, because the former comes later in acquisition than the latter.

\section{Research Question}

In order to investigate the possible contributions of syntactic knowledge, mainly DMs and relative clauses, this study aimed to investigate the effectiveness of developing such knowledge on students' performance in reading comprehension. The study addressed the following question:

1- To what extent does teaching DMs and relative clauses affect the reading comprehension of intermediate EFL learners?

\section{Research Methodology}

\subsection{Participants}

In order to undertake the study, two groups of students were selected, one as the control group and the other one as the experimental group. Eighty four students were assigned into two classes in two high schools who were segregated based on their genders. Participants' age was between 15 and 16 years old. The researchers assigned 40 students in the control group and41 students in the experimental group.

\subsection{Design}

In this study, since the researchers did not change any participants of classes and did not select or randomize the subjects, a quasi-experimental design was applied. The following table shows the design of the present study clearly:

Table 4. Design of the Study

\begin{tabular}{|c|c|c|c|}
\hline Groups & Pre-test & Treatment & Post-test \\
\hline A & 01 & $X$ & 02 \\
B & 01 & - & 02 \\
\hline
\end{tabular}


As it is depicted in Table 4, two groups participated in this study. Considering participants' role, one group was assigned as experimental and the other group played the role of control group. Only did experimental group receive treatment. Finally, both groups were given the pretest and posttest.

\subsection{Materials}

Two different materials, instructional and testing, were used in this study. The instructional materials were extracted from standard passages for EEU (entrance exam of universities) which contain standardized tests already validated. There are 80 standard passages for high school students which are very close to questions which have been used in recent years in Kiasalar's (2011) book.

\subsubsection{Instruction for the experimental groups}

As it was mentioned in introduction, the aim of this study was to discover the impact of discourse markers and relative clauses on reading comprehension ability, so instructional materials germane to this purpose must include reading passages and formal grammar teaching. Students were taught formal grammatical instructions as well as practicing them in passages. DMs and relative clauses were the most striking syntactic points in this study, so the instructor used the techniques mentioned above to teach and explain aforementioned specific grammatical points.

\subsection{Data analysis}

In order to determine if any development in reading comprehension scores occurred between the pre-test and the posttest, t-test was used. To check students' progress in the experimental group, paired sample test was run. The same kind of test was run to determine the possible development in control group, too. Eventually, an independent sample test was run to compare the performance of the experimental and control group in the post test.

\section{Findings and Discussion}

\subsection{Results}

Research Question: Does teaching DMs and relative clauses affect the reading comprehension of intermediate EFL learners?

\subsubsection{Data analysis prior to the experiment}

An independent sample t-test was run to compare students' knowledge of reading comprehension in experimental and control groups. The result of this analysis revealed that these groups did not differ significantly since $P$ is $.99>05$.

Table 5. Independent Samples Test

\begin{tabular}{|ll|c|c|c|c|c|}
\hline & & \multicolumn{5}{|c|}{ t-test for Equality of Means } \\
\cline { 2 - 7 } Performance & Equal variances assumed & .006 & 82 & .995 & .004 & Std. Error Difference \\
\cline { 2 - 7 } & Equal variances not assumed & .006 & 81.70 & .995 & .004 & .73 \\
\hline
\end{tabular}

To check students' homogeneity prior to the experiment, the data obtained by means of pretest was analyzed through running an independent samples t test. Table 5 illustrates the $p$ value of the comparison of means is $.995>.05$, thus it can be claimed that students in experimental and control groups are almost at the same level regarding their reading comprehension performance.

\subsubsection{Data Analysis}

In order to investigate the significance of the difference in each group, a paired samples t-test had to be used. Students' 
performance in pretest was compared with their performance in post-test in both experimental and control groups. The results of t-test revealed that developing the knowledge of DMs and relative clauses had a statistically significant effect on students' performance in reading comprehension.

Table 6. Paired Samples Statistics for Experimental Groups

\begin{tabular}{|ll|c|c|c|c|}
\hline & Mean & $\mathrm{N}$ & Std. Deviation & Std. Error Mean \\
\hline \multirow{2}{*}{ Pair 1 } & performance2 & 9.20 & 40 & 2.82 & .44 \\
& performance1 & 7.55 & 40 & 3.30 & .52 \\
\hline
\end{tabular}

Table 6 shows the mean score of the experimental group in pretest and post-test which has been increased from 7.55 to 9.20 .

Table 7.Paired Samples Test for Experimental Groups

\begin{tabular}{|l|c|c|c|c|c|}
\hline & \multicolumn{2}{|c|}{ Paired Differences } & $t$ & Df & P \\
\hline & $\mathrm{M}$ & $\mathrm{SD}$ & & & \\
\hline Pair 1 performance2 - performance1 & 1.65 & 1.36 & 7.62 & 39 & .000 \\
\hline
\end{tabular}

As it is depicted in Table 7, p value is zero which means that the treatment on the experimental group has had a statistically significant effect.

Table 8. Paired Samples Statistics for the Control Group

\begin{tabular}{|ll|c|c|c|c|}
\hline & Mean & $\mathrm{N}$ & Std. Deviation & Std. Error Mean \\
\hline \multirow{2}{*}{ Pair 1 } & performance2 & 7.77 & 44 & 2.76 & .41 \\
& performance1 & 7.54 & 44 & 3.42 & .51 \\
\hline
\end{tabular}

Table 8 shows the mean score of the control group in pretest and post-test which has been increased from 7.54 to 7.77 .

Table 9. Paired Samples Test for the Control Group

\begin{tabular}{|l|c|c|c|c|c|}
\hline \multicolumn{2}{|c|}{ Paired Differences } & t & df & P \\
\hline & $M$ & SD & & & \\
\hline Pair 1 & .22 & 1.11 & 1.34 & 43 & .18 \\
\hline
\end{tabular}

As it is shown in Table 9, $p$ is .18>.05 which means that students in the control group did not have a significant difference from pretest to the post-test.

In order to compare the performance of students in experimental and control groups, an independent samples ttest was run to determine the effectiveness of the instruction on the experimental group. Table 10 depicts the following information.

Table 10: Independent Samples Test

\begin{tabular}{|cl|c|c|c|c|c|}
\hline & & \multicolumn{5}{|c|}{ t-test for Equality of Means } \\
\cline { 2 - 7 } & & $\mathrm{T}$ & $\mathrm{df}$ & $\mathrm{P}$ & Mean Difference & $\begin{array}{c}\text { Std. Error } \\
\text { Difference }\end{array}$ \\
\hline \multirow{2}{*}{ Performance } & Equal variances assumed & 2.3 & 82 & .022 & 1.42 & .61 \\
& Equal variances not assumed & 2.33 & 80.92 & .022 & 1.42 & .61 \\
\hline
\end{tabular}

The comparison of mean scores of experimental and control groups in post-test proved that although they did not have any statistically significant difference at the outset of the experiment, the experimental group outperformed the control group since $p$ is $.02<.05$. 


\section{Discussion}

A corpus of research has substantiated that syntactic knowledge affects students' understanding of reading positively. This study revealed improvement of students' performance in reading comprehension regarding syntactic knowledge namely DMs and relative clauses. The findings of this study showed that although students had almost similar mean scores at the beginning, the experimental group outperformed the control group at the end. They confirmed previous research (Bentin 1990; Bowey, 1986a; Menyuk, 1991), on the positive effect of instruction on learners' development of syntactic knowledge and its effect on reading comprehension performance.

Nation and Snowling (2000) found a strong correlation between syntactic awareness skills and reading comprehension. These and other L1 studies (Ehri \& Wilce, 1980; Forrest-Pressley \& Waller, 1984; Morais, Cary, Alegria, \& Bertelson, 1979; Rego \& Bryant, 1993) indicate that the relationship between syntactic abilities and reading comprehension is still controversial.

The presence of a relationship between syntactic awareness and reading comprehension has been well indicated in correlational studies. Regarding L1 reading research, it has been proved that syntactic awareness is a statistically significant predictor of students 'reading comprehension performance and ongoing reading comprehension (Bowey, 1986a, 1986b; Dreher \& Zenge, 1990).

Among recent studies on children's L2 reading development and syntactic abilities, Martohardjono, Otheguy, Gabriele, and Troseth (2005) focused on structures that are considered to be milestones in the development of monolingual children, specifically coordination and subordination. The team investigated whether bilingual children with a strong knowledge base in their L1 (Spanish) acquire reading comprehension in L2 (English) better than those with weaker L1 syntax. Their second question concerned the degree to which a strong syntactic base in L2 contributes to listening comprehension in L2, and if this is a -more significant factor than the corresponding base in the L1 (Martohardjono et al., 2005).

In order to examine the relevance of syntactic knowledge and reading comprehension performance in L2, Rabia and Siegel (2002) assessed the role of syntactic knowledge in reading comprehension of 56 bilingual Arab-Canadian children aged 9-14 and found a correlation of .57. Alderson (1993) reviewed the data from the English Language Testing Services (ELTS) Revision Project and found a considerable overlap between scores on the grammar test and the reading test, which led him to propose a significant role of grammar in L2 reading. In a similar vein, in Kuhn and Stahl's (2003) review of theories and research on reading instruction, training $L 2$ readers to parse sentences into meaningful phrases and providing them with already syntactically segmented texts were revealed to promote $L 2$ reading comprehension to a significant level. That is to say, the abilities to identify syntactic roles of words, dissect sentences into meaningful chunks, and help the students recognize the syntactic structure of a sentence seem to contribute to the construction of meaning from the text.

Comparing the relative importance of grammar with that of other $L 2$ reading components, such as background knowledge and vocabulary tempted researchers to analyze students' grammatical knowledge and its impact on reading performance in different studies. Barnett's (1986) study revealed that the relative contribution made by grammar and vocabulary to $\mathrm{L} 2$ reading, grammatical knowledge was shown to have a comparable effect on $\mathrm{L} 2$ comprehension to that of vocabulary knowledge.

\section{Conclusions and Implications of the Findings for EFL/ESL Contexts}

The most striking issue highlighted by the findings of this study is the role which is given to grammar by practicing through reading passages. As Rutherford (1987) states, grammar should not be taught for its own sake, but it should be regarded as a means to help learners manage their own learning and use their knowledge about isolated structure to understand the discourse.

According to the findings of this study, it is very important for teachers to have a clear idea about the significance of grammar in English classes and its impact on skills such as reading. Having explicit and implicit knowledge of grammar improves students' performance in reading comprehension tests.

The following suggestions drawn from this study cannot be used as one hundred percent guaranteed ways of teaching and learning of reading passages successfully, but they may help teachers and students to enhance their understanding of reading passages by means of focusing on syntactic points. This study was conducted to enhance the understanding of the impact of syntactic points like DMs and relative clauses on reading comprehension performance. Hence, the findings of this research put forward the following implications for EFL teachers and earners, syllabus designers, and test developers. 
The implications of the study for classroom reading/foreign language instruction in Iran are manifold. The immediate application of the findings of this research is for EFL teachers. The most significant skill that EFL teachers have to practice in classrooms is reading comprehension; hence the problems in this realm have been raised dramatically. Teachers can concentrate on specific structural points in every passage and teach them while working on other sub-skills like pronunciation and vocabulary. This needs syllabus designers to devise passages which contain specific syntactic points. Textbooks which have such implicit syntactic points can be written. Furthermore, test developers have to focus on assessing the same grammatical points in questions.

\section{References}

Alderson, J. C. (1993). The relationship between grammar and reading in an English for academic purposes test battery. In D. D. Chapelle (Ed.), A new decade of language testing research: Selected papers from the 1990 Language Testing Research Colloquium (pp. 203-219). Alexandria: VA: TESOL.

Anderson, R. C., \& Pearson, P. D. (1982). A shcema theoretic view of basic processes in reading comprehension. New York: Longman.

Barnett, M. A. (1986). Syntactic and lexical/ semantic skills in foreign language reading: Importance and interaction. The Modern Language Journal, 70(1), 343-349.

Bentin, S. D. (1990). Syntactic competence and reading ability in children. Journal of Experimental Child Psychology, 48(2), 147-172.

Berman, R. (1984). Syntactic components of the foreign language learning process. In J. C. Urqhart (Ed.), Reading in a foreign language (pp. 53-75). New York: Longman.

Bernhardt, E., \& James, C. (1987). The teaching and testing of comprehension in foreign language learning. In D. Bickbichler (Ed.), Proficiency, policy and professionalism in foreign language education (pp. 65-81). Lincolnwood: National Textbook Company.

Bowey, J. A. (1986a). Syntactic awareness and verbal performance from preschool to fifth grade. Journal of Psycholinguistic Research, 41(2), 285-308.

Bowey, J.A. (1986b). Syntactic awareness in relation to reading skill and ongoing reading comprehension monitoring. Journal of Experimental Child Psychology, 41(2), 282-299.

Brown, H. (2001). Teaching by principles: An interactive approach to language pedogogy. New York: Longman.

Carrell, P. L. (1983). Three components of background knowledge in reading comprehension. Language Learning, 33(2), pp. 183-239.

Chastain, K. (1988). Developing second language skills. Virginia: Harcourt Brace Jovanovic.

Cromer, W., \& Wiener, M. (1966). Idiosyncratic response patterns among good and poor readers. Journal of Consulting Psychology, $30(1), 1-10$.

Dreher, M. J., \& Zenge, S.D. (1990). Using metalinguistic awareness in first grade to predict reading achievement in third and fifth grades. Journal of Educational Research, 84(1), 13-21.

Ehri, L. C., \& Wilce, L. S. (1980). The influence of orthography on readers' conceptualization of the phonemic structure of words. Applied Psycholinguistics, 1(3), 371-385.

Ellis, N. (2008). Implicit and explicit knowledge about language. In J. Cenoz, \& N. Hornberger, Encyclopaedia of Language and Education (pp. 119-131). New York: Springer.

Eskey, D. E., \& Grabe, W. (1988). Interactive models for second language reading: perspectives on instruction. In J. D. P. Carrell, Interactive approaches to second language reading. Cambridge: Cambridge University Press.

Eskey, D. E. (1970). A new technique for the teaching of reading to advanced students. TESOL Quarterly, 4(4), pp. 315-321.

Faerch, C., \& Gasper, K. (1986). The role of context in second language learning. Applied Linguistics, 7(1), 258-274.

Forrest-Pressley, D. F., Waller, T. G., \& Pressley, M. (1984). A comment About Jacobs and Paris. Educational Psychologist, 24(2), 207210.

Fraser, B. (1999). What are discourse markers. Journal of Pragmatics, 14(1), 931-952.

Halliday, M. (1976). Cohesion in English. London: Longman.

Kiasalar, R. (2011). Let's not scared from texts. Tehran: Shabghare.

Kuhn, M. R., \& Stahl, S. A. (2003). Fluency: A review of developmental and remedial practices. Journal of Educational Psychology, 95(1), 3-21.

Levinson, S. C. (1983). Pragmatics. Cambridge: Cambridge University Press.

Long, M., \& Richards, J. (1987). Methodology in TESOL. Boston: Heinle \& Heinle.

Martohardjono, G., Otheguy, R., Gabriele, A., \& Troseth, E. (2005). The role of syntax in reading comprehension: A study of bilingual readers. Proceedings of the 4th International Symposium on Bilingualism. (pp. 1522-1544). Somerville: MA: Cascadilla.

Menyuk, P. C. (1991). Predicting reading problems in at-risk children. Journal of Speech and Hearing Research, 34 (4), 893-903.

Mokhtari, K., \& Niederhauser, D. (2013). Vocabulary and syntactic knowledge factors in 5th grade students' reading comprehension. International Electronic Journal of Elementary Education, 5(3), 157-170.

Morais, L. Cary, Alegria, J., \&Bertelson, P. (1979). Does awareness of speech as a sequence of phones arise spontaneously? Cognition, 7(2), 323-331.

Nation, K., \& Snowling , M. J. (2000). Factors influencing syntactic awareness skills in normal readers and poor comprehenders. Applied Psycholinguistics, 21(2), 229-241.

Nunan, D. (1999). Second language teaching \& learning. Boston: Heinle \& Heinle. 
O "stman, J. O. (1995). Pragmatic particles twenty years after. In Wa ${ }^{\circ}$ vik, ,. S.-K. Tanskanen, \& R. B., Hiltunen, (Eds.), Organization in discourse (pp. 95-108).Turkuensia: Anglicana.

Pica, T. (1985). The selective impact of instruction second language acquisition. Applied Linguistics, 6(2), 214-222.

Rabia, A. S., \& Siegel, S. L. (2002). Reading, syntactic, orthographic, and working memory skills of bilingual Arabic-English speaking Canadian children. Journal of Psycholinguistic Research, 31(1), 661-678.

Radford, A. (2004). Minimalist syntax exploring the structure of English. London: Cambridge University Press.

Redeker, G. (1990). Ideational and pragmatic markers. Journal of Pragmatics, 14(3), 367-381.

Rego, L. L. B., \& Bryant, P. E. (1993). The connection between phonological, syntactic and semantic skills and children's reading and spelling. European Journal of Psychology of Education, 3(8), 235-246.

Rutherford, W. (1987). Second language grammar: learning and teaching. New York: Longman.

Schorup, L. C. (1985). Common discourse particles in English conversation. New York: Garland.

Shankweiler, D., \& Crain, S. (1986). Syntactic complexity and reading acquisition. Haskins Laboratories Status Report on Speech Research, 86-87.

Vogel, S. A. (1975). Syntactic abilities in normal and dyslexic children. Baltimore: University Park Press.

Zarei, A. A. (2007). Teaching methodology. Qazvin: Sayegostar Publication.

Zwicky, M. A. (1985). Clitics and particles. Language, 61(1), 283-305. 